\title{
Connectivity among fragmented populations of a habitat-forming alga, Phyllospora comosa (Phaeophyceae, Fucales) on an urbanised coast
}

\author{
Melinda A. Coleman ${ }^{1,2, *}$, Brendan P. Kelaher ${ }^{2,3}$ \\ ${ }^{1}$ Center for Marine Bioinnovation, University of New South Wales, New South Wales 2052, Australia \\ ${ }^{2}$ Batemans Marine Park, Department of Environment and Climate Change, Burrawang St., Narooma, New South Wales 2546, \\ Australia \\ ${ }^{3}$ Department of Environmental Sciences and Institute for Water and Environmental Resource Management, \\ University of Technology Sydney, PO Box 123, Broadway, New South Wales 2007, Australia
}

\begin{abstract}
Despite a growing body of knowledge on the ecological consequences of loss and fragmentation of habitat-forming macroalgae, little is known about the genetic implications of such losses. Here, we investigate the genetic consequences of fragmentation caused by the loss of the habitat-forming macroalga Phyllospora comosa from $70 \mathrm{~km}$ of urbanised coastline in Sydney, Australia. Contrary to predictions, there appeared to be substantial connectivity among fragmented populations, although spatial autocorrelation analysis revealed that this may be an artifact of allele size homoplasy beyond scales of $\sim 80 \mathrm{~km}$. Genetic differentiation was not related to geographic separation of populations. This may be explained by the nature of prevailing currents (East Australian Current) that promote nonlinear dispersal in 'leaps', sourcing propagules from one area and depositing them via eddies that either come ashore or disperse. Populations that were tens of kilometers apart were often genetically different, which was likely due to barriers to dispersal, such as sandy beaches and mouths of estuaries, or rapid fertilization and recruitment of zygotes on small spatial scales. Our research provides a basis for designing a rehabilitation program for populations of Phyllospora comosa, with appropriate consideration of genetic diversity and structure.
\end{abstract}

KEY WORDS: Microsatellites · Fucoid · Phyllospora comosa · Algae · Dispersal · Connectivity · Decline

Resale or republication not permitted without written consent of the publisher

\section{INTRODUCTION}

Loss of subtidal macroalgal forests is an increasingly common problem in temperate marine ecosystems (Steneck et al. 2002). Anthropogenic stressors such as climate change, eutrophication, urbanisation and pollution, as well as episodic events such as grazing, storms and disease are responsible for extensive losses of habitat-forming algae worldwide (see reviews by Dayton et al. 1998, Steneck et al. 2002, Airoldi \& Beck 2007). Although direct and indirect ecological effects of losses of macroalgal forests are well studied, the genetic consequences of large-scale loss of habitatforming macroalgae remain poorly understood.

Geographic isolation or spatial separation of once continuous forests is a likely consequence of both natural and anthropogenic stressors in subtidal macroalgal forests. Although fragmentation may have few conspicuous short-term consequences, fragmented populations may experience long-term impacts on dispersal and gene flow, depending on factors such as the separation distances among fragments of forest relative to the scale of dispersal of propagules, and the presence, strength and direction of vectors of dispersal between populations (e.g. currents). In cases of low levels of dispersal, populations can become genetically distinct through effects including mutation, selection and genetic drift. With little or no gene flow, fragmented populations may become morphologically, physiologically or ecologically divergent, suffer from inbreeding depression, or ultimately become extinct (e.g. Soule 1980, Gabriel et al. 1993, Lande 1993, 
Frankham 1998, Saccheri et al. 1998, Tanaka 2000, Keller \& Waller 2002). It is critical, therefore, to understand levels of connectivity among fragmented populations of habitat-forming macroalgae to help elucidate the processes responsible for precipitating losses in the first place. This may also help in the accurate prediction of whether natural recolonisation or recovery of populations is likely to occur, and therefore aid in the design and implementation of rehabilitation programs.

The monotypic Phyllospora comosa (Labillardière) C. Agardh, hereafter referred to as Phyllospora, is an important habitat-forming macroalga on shallow subtidal reefs ( 0 to $5 \mathrm{~m}$ depth) in eastern Australia, where it often accounts for $100 \%$ of canopy cover (Coleman et al. 2008a). Along the coast of New South Wales (NSW), populations of this perennial, dioecious fucoid alga have approximately equal ratios of male and female individuals (M. A. Coleman unpubl. data), and reproduce throughout the year (M. A. Coleman pers. obs.) via release of sperm and external fertilisation of eggs that remain attached to the female thallus. Since the 1940s, Phyllospora has disappeared from urbanised coastlines around Sydney, leaving a $70 \mathrm{~km}$ gap in its distribution (Coleman et al. 2008a). Indeed, a recent comprehensive SCUBA, snorkel and literature survey did not find a single individual growing along $70 \mathrm{~km}$ of Sydney reefs, despite being common half a century ago (Coleman et al. 2008a). Phyllospora is still abundant north and south of Sydney, however, accounting for up to $100 \%$ of canopy cover on shallow subtidal reefs in these areas. As is the case with other macroalgae (e.g. Faugeron et al. 2005), dispersal and gene flow across the gap in distribution may be restricted. Moreover, the relatively small population of Phyllospora north of Sydney (extending to $\sim 420 \mathrm{~km}$ of coastline) may exhibit increased inbreeding, which may ultimately compromise population persistence. Here, we use 7 polymorphic microsatellite markers to characterise genetic diversity and structure of this important subtidal macroalga, and determine whether its decline from such large expanses of coastline has genetic consequences for the fragmented northerly population.

\section{MATERIALS AND METHODS}

Phyllospora was collected in 2007 from shallow subtidal reefs to the north and south of the $70 \mathrm{~km}$ gap in Phyllospora distribution. In each of the north and south regions, we collected small, unfouled portions of the thallus ( $10 \mathrm{~cm}$ long) of a total of 392 mature, adult individuals from each of 2 sites (kilometres apart) in each of 3 locations (tens to hundreds of kilometers apart). Sites to the north of Sydney, paired by location, were Fingal Bay and Anna Bay, Bateau Bay and Terri- gal, and Pearl Beach and Palm Beach, while sites to the south of Sydney were Shellharbour and Kiama, Mollymook and Ulladulla, and Dalmeny and Mystery Bay (Fig. 1). At each site, individuals were haphazardly sampled from a $50 \times 10 \mathrm{~m}$ area of reef, with a minimum distance of at least $1 \mathrm{~m}$ between individuals collected. Algal material was rinsed in freshwater and dried in silica gel for later analysis. Genomic DNA was extracted using a Nucleospin multi 96 plant kit (Macherey-Nagel) on material that was freeze-dried and ground. The quality of a random sample of DNA from each plate was assessed by amplification using actin primers and the quantity estimated via picogreen fluorescence. DNA was diluted to $1: 50$ or $1: 100$ prior to PCR. A total of 7 microsatellite loci (see Coleman et al. 2008b) were amplified in $10 \mu \mathrm{l}$ reaction mixtures containing $0.2 \mathrm{mM}$ dNTP (deoxynucleoside triphosphate), $1 \times \mathrm{PCR}$ buffer, $1.5 \mathrm{mM} \mathrm{MgCl}_{2}, 1 \mathrm{U}$ immolase (a hot-start polymerase, BIOLINE), $2 \mu \mathrm{g}$ BSA, $100 \mathrm{nM}$ of each unique forward and HEX labelled reverse primer, and $\sim 0.05 \mathrm{ng}$ of genomic DNA, and the volume was made up to $10 \mu$ l with water. Reaction mixtures were run on an Eppendorf thermo-

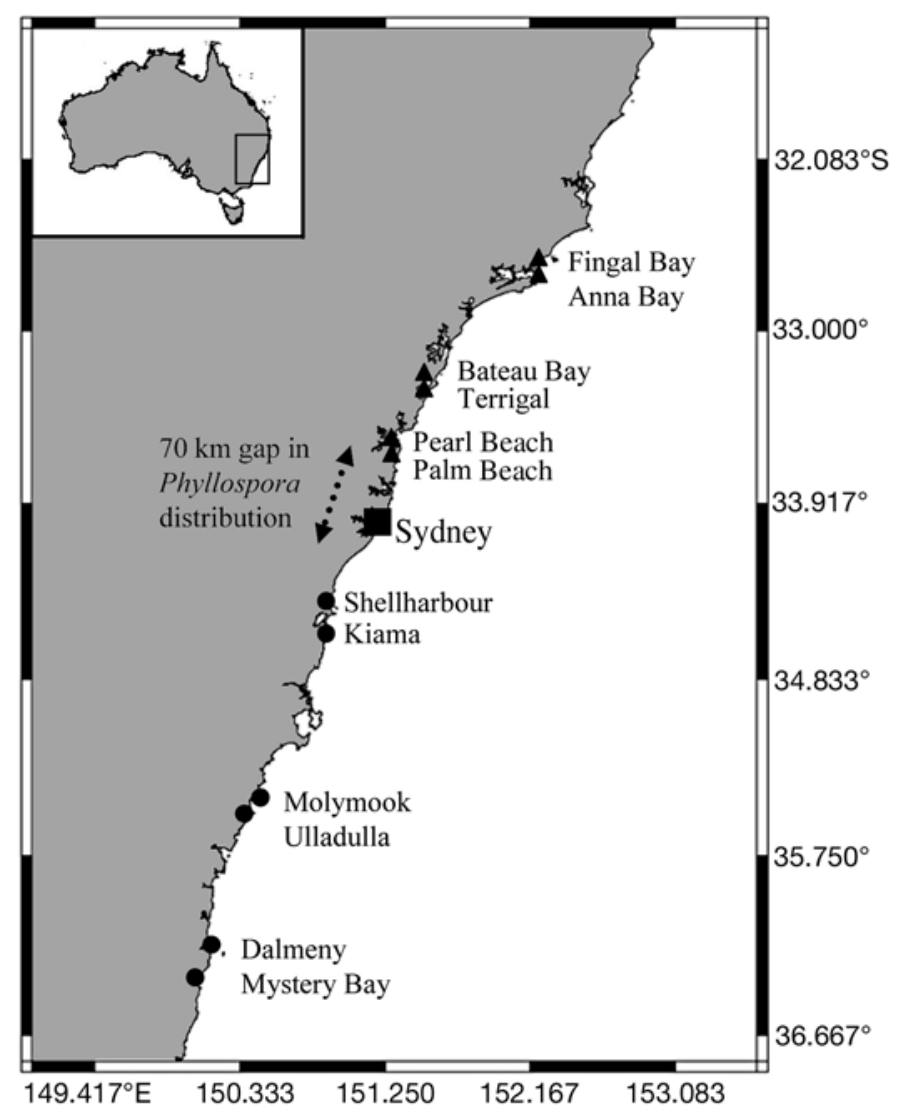

Fig. 1. Map of Australia (inset) and central New South Wales showing locations sampled to the north $(\mathbf{\Delta})$ and south (๑) of Sydney 
cycler at the following conditions: $95^{\circ} \mathrm{C}$ for $7 \mathrm{~min}, 6$ cycles of $95^{\circ} \mathrm{C}$ for $30 \mathrm{~s}, 53^{\circ} \mathrm{C}$ for $60 \mathrm{~s}$, and $72^{\circ} \mathrm{C}$ for $60 \mathrm{~s}$, with the annealing temperature being reduced by $1{ }^{\circ} \mathrm{C}$ per cycle; 30 cycles of $95^{\circ} \mathrm{C}$ for $30 \mathrm{~s}, 47^{\circ} \mathrm{C}$ for $60 \mathrm{~s}$, and $72^{\circ} \mathrm{C}$ for $60 \mathrm{~s}$, with a final extension of $72^{\circ} \mathrm{C}$ for $10 \mathrm{~min}$. Products were run on a $1.5 \%$ agarose gel to check for amplification before being run on an ABI 3730 Genescan. Allele sizes were determined using Peak Scanner software (Applied Biosystems).

Prior to statistical analyses, we checked the data for typographical and genotyping errors as well as the presence of null alleles using the program MICROCHECKER (www.microchecker.hull.ac.uk/index.jsp, van Oosterhout et al. 2004). By identifying specific patterns in the data (e.g. deficiencies and excesses of particular genotypes) that are unique to each of the above genotyping problems, this program is able to distinguish such problems from 'real' departures from panmixia (van Oosterhout et al. 2004). Patterns of genetic diversity were characterised using a number of different descriptive measures. The total number of alleles, number of unique alleles, allele frequencies, and observed $\left(H_{\mathrm{o}}\right)$ and expected heterozygosities $\left(H_{\mathrm{e}}\right)$ were estimated using GENETIX ver. 4.04 (www.genetix. univ-montp2.fr/genetix/genetix.htm, Belkhir et al. 2000). In addition, we tested for linkage disequilibrium and Hardy-Weinberg equilibrium at each locus and across all loci using FSTAT 1.2 (www2.unil.ch/ popgen/softwares/fstat.htm, Goudet 1995). Patterns of genetic structure were visualized using neighbour joining trees made in PHYLIP (http://evolution. genetics.washington.edu/phylip.htm, Felsenstein 2002) and drawn in TREEVIEW (http://taxonomy.zoology. gla.ac.uk/rod/treeview.html, Page 1996). These patterns were produced using a matrix of Reynolds' genetic distances (Reynolds et al. 1983). The relative strength of groupings was measured using bootstrap values (PHYLIP; Felsenstein 2002). Genetic structure was estimated by testing Weir and Cockerham's $F_{\mathrm{ST}}$ (Wright's fixation index, a measure of genetic differentiation) and $F_{\mathrm{IS}}$ (a measure of inbreeding within populations) estimates (Weir \& Cockerham 1984) using permutation tests (1000 permutations, FSTAT 1.2; Goudet 1996). Pairwise $F_{\mathrm{ST}}$ were also estimated between sites. A sequential Bonferroni correction (Rice 1989) was used to examine significance levels for pairwise tests. We did not assume random mating in these analyses, so genotypes (rather than alleles) were permuted. To determine the percentage of variation at each spatial scale, we carried out analyses of molecular variance (AMOVA) in ARLEQUIN ver. 3.00 (http://lgb.unige. ch/arlequin, Excoffier et al. 2005) using $F$ statistic and $\mathrm{p}<0.05$. To test at the 3 hierarchical spatial scales (regions, locations and sites), we did 2 separate AMOVAs. First, we tested for genetic variability between regions (north and south) and among sites within regions. A second AMOVA tested for genetic variability between regions and among locations within regions. We did not assume a stepwise mutation model. Tests of isolation by distance were done via a Mantel test for all location data using the program IBD (www.bio.sdsu.edu/pub/andy/IBD.html, Bohonak 2002). Analyses of spatial autocorrelation using all locations were done in GenAlEx (www.anu.edu.au/BoZo/ GenAlEx, Peakall \& Smouse 2006). At each distance class, positive $\mathrm{r}$ values indicate positive correlation between genotypes (i.e. genotypes are more similar to one another than can be expected by chance), whereas negative $r$ values indicate no or a random relationship among genotypes.

Table 1. Phyllospora comosa. Number of individuals sampled (n), expected and observed heterozygosity $\left(H_{\mathrm{e}}\right.$ and $\left.H_{\mathrm{o}}\right)$ and $F_{\mathrm{IS}}$ (a measure of inbreeding within populations) for each site north and south of Sydney and for each locus. ${ }^{*}$ All values significant $(\mathrm{p}<0.0005)$

\begin{tabular}{|c|c|c|c|c|c|c|c|c|c|c|c|c|}
\hline \multirow{2}{*}{ Region } & \multirow{2}{*}{ Site } & \multirow{2}{*}{$\mathrm{n}$} & \multirow{2}{*}{$H_{\mathrm{e}}$} & \multirow{2}{*}{$H_{\mathrm{o}}$} & & & & & \multicolumn{4}{|l|}{$F_{\mathrm{IS}}$} \\
\hline & & & & & $\begin{array}{c}\text { All } \\
\text { loci }^{*}\end{array}$ & $\begin{array}{l}\text { SSR11 } \\
\text { P8 }\end{array}$ & $\begin{array}{c}\text { SSR11 } \\
\text { P51 }\end{array}$ & $\begin{array}{c}\text { SSR1 } \\
\text { P18 }\end{array}$ & $\begin{array}{c}\text { SSR1 } \\
\text { P32 }\end{array}$ & $\begin{array}{c}\text { SSR1 } \\
\text { P95 }\end{array}$ & $\begin{array}{c}\text { SSR1 } \\
\text { P21 }\end{array}$ & $\begin{array}{c}\text { SSR11 } \\
\text { P18 }\end{array}$ \\
\hline \multirow[t]{6}{*}{ North } & Fingal Bay & 32 & 0.436 & 0.293 & 0.342 & 0.44 & 0.21 & 0.49 & 0.65 & 0.11 & 0.38 & 0.43 \\
\hline & Anna Bay & 32 & 0.399 & 0.288 & 0.294 & 0.49 & 0.06 & -0.02 & 0.88 & 0.03 & 0.33 & 0.41 \\
\hline & Terrigal & 32 & 0.497 & 0.297 & 0.415 & 0.56 & 0.29 & 0.81 & 0.57 & -0.12 & 0.35 & 0.42 \\
\hline & Bateau Bay & 32 & 0.508 & 0.350 & 0.327 & 0.34 & 0.31 & 0.52 & 0.64 & 0.05 & 0.08 & 0.42 \\
\hline & Pearl Beach & 40 & 0.422 & 0.255 & 0.407 & 0.59 & 0.51 & 0.70 & 0.78 & 0.08 & 0.08 & 0.39 \\
\hline & Palm Beach & 32 & 0.467 & 0.185 & 0.615 & 0.85 & 0.36 & 0.95 & 1.00 & 0.04 & 0.35 & 0.73 \\
\hline \multirow[t]{6}{*}{ South } & Shellharbour & 32 & 0.460 & 0.268 & 0.432 & 0.37 & 0.40 & 0.87 & 0.89 & 0.00 & 0.39 & 0.71 \\
\hline & Kiama & 32 & 0.451 & 0.244 & 0.473 & 0.54 & 0.72 & 0.36 & 1.00 & 0.11 & 0.45 & 0.68 \\
\hline & Mollymook & 32 & 0.444 & 0.174 & 0.620 & 0.62 & 0.57 & 1.00 & 1.00 & 0.11 & 0.37 & 0.71 \\
\hline & Ulladulla & 32 & 0.507 & 0.291 & 0.442 & 0.64 & 0.47 & 0.32 & 0.82 & 0.19 & 0.00 & 0.56 \\
\hline & Dalmeny & 32 & 0.592 & 0.326 & 0.430 & 0.47 & 0.60 & 0.83 & 0.79 & -0.08 & -0.18 & 0.43 \\
\hline & Mystery Bay & 32 & 0.497 & 0.339 & 0.332 & 0.42 & 0.36 & 0.73 & 0.71 & 0.05 & -0.04 & 0.23 \\
\hline
\end{tabular}




\section{RESULTS}

There was no evidence of null alleles at any locus when data were checked with MICRO-CHECKER. There was also no evidence of linkage disequilibrium between any pair of loci. Observed heterozygosities were smaller than expected at all sites (Table 1). All but one locus deviated from the Hardy-Weinberg

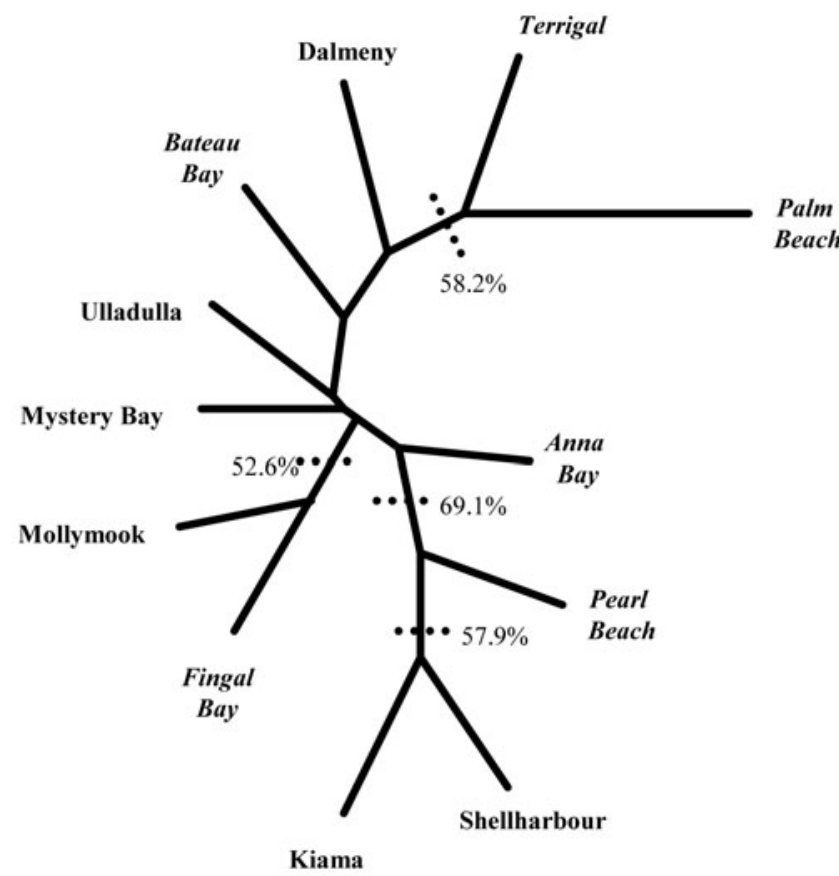

Fig. 2. Neighbour joining tree (based on Reynolds distance) showing relationships among the 12 sites. Bootstrap values $>50 \%$ are shown with dotted lines. Sites to the north of Sydney are in italics equilibrium, suggesting nonrandom mating, and this was consistent at the majority of sites. The exception to this was P95, which was in Hardy-Weinberg equilibrium at $77 \%$ of the sites. All sites were characterised by an excess of homozygotes with significantly large, positive $F_{\text {IS }}$ estimates (Table 1 ) indicative of inbreeding. The number of alleles per site ranged from 26 to 39 and was not significantly different among sites (ANOVA, p > 0.05).

A neighbour joining tree revealed that sites from the north and south of Sydney often grouped together (Fig. 2), although bootstrap values were weak $(<70 \%)$. Pairwise $F_{\mathrm{ST}}$ tests between all pairs of sites confirmed that populations from opposite regions (north vs. south) were just as genetically different (70\% of pairwise tests significant, Table 2) as were populations within regions $(60 \%$ of pairwise tests significant; Table 2), with the average pairwise $F_{\mathrm{ST}}$ within regions $\left(F_{\mathrm{ST}}=0.054\right)$ being almost identical to that between regions $\left(F_{\mathrm{ST}}=0.052\right)$. There was a significantly large amount of genetic variation among individuals within each site (AMOVA, 94.75\%, p < 0.00001; Table 3). A much smaller but significant amount of variation was explained by variation among sites (AMOVA, 5.43\%, p $<0.00001, F_{\mathrm{ST}}=$ 0.048 ; Table 3 ). An insignificant amount of genetic variation was explained by variations between north and south regions (AMOVA, $\mathrm{p}=0.577, F_{\mathrm{ST}}=0.016$; Table 3). A separate AMOVA to compare locations within regions also showed insignificant genetic variation between north and south populations, with some variation occurring among locations (AMOVA, $4.33 \%$, $\mathrm{p}<0.00001, F_{\mathrm{ST}}=0.039$; Table 3), and most variation occurring among sites within locations (AMOVA, $96.44 \%, \mathrm{p}<0.00001, F_{\mathrm{ST}}=0.048$; Table 3$)$. The $F_{\mathrm{ST}}$

Table 2. Genetic variability in Phyllospora comosa populations. Pairwise $F_{\mathrm{ST}}$ estimates between all pairs of sites (significant values after the Bonferroni sequential correction are in bold). Pairwise $F_{\mathrm{ST}}$ estimates between sites from opposite regions are highlighted in grey. Other estimates represent comparisons between sites within north or within south regions. FB: Fingal Bay, AB: Anna Bay, BB: Bateau Bay, T: Terrigal, PB: Pearl Beach, Pa: Palm Beach, S: Shellharbour, K: Kiama, M: Mollymook, U: Ulladulla, D: Dalmeny, and My: Mystery Bay

\begin{tabular}{|c|c|c|c|c|c|c|c|c|c|c|c|c|}
\hline & \multicolumn{6}{|c|}{ North } & \multicolumn{6}{|c|}{ - South } \\
\hline & FB & $A B$ & $\mathrm{BB}$ & $\mathrm{T}$ & PB & $\mathrm{Pa}$ & $\mathrm{S}$ & $\mathrm{K}$ & $\mathrm{M}$ & $\mathrm{U}$ & $\mathrm{D}$ & My \\
\hline FB & - & & & & & & & & & & & \\
\hline $\mathrm{AB}$ & 0.021 & - & & & & & & & & & & \\
\hline BB & 0.047 & 0.058 & - & & & & & & & & & \\
\hline $\mathrm{T}$ & 0.064 & 0.090 & 0.006 & - & & & & & & & & \\
\hline PB & 0.050 & 0.050 & 0.028 & 0.072 & - & & & & & & & \\
\hline $\mathrm{Pa}$ & 0.101 & 0.098 & 0.042 & 0.034 & 0.089 & - & & & & & & \\
\hline $\mathrm{S}$ & 0.072 & 0.036 & 0.024 & 0.066 & 0.027 & 0.059 & - & & & & & \\
\hline K & 0.118 & 0.084 & 0.051 & 0.089 & 0.042 & 0.113 & 0.030 & - & & & & \\
\hline M & 0.005 & 0.090 & 0.012 & 0.026 & 0.073 & 0.067 & 0.094 & 0.148 & - & & & \\
\hline U & 0.036 & 0.046 & 0.020 & 0.072 & 0.045 & 0.102 & 0.049 & 0.091 & 0.034 & - & & \\
\hline D & 0.062 & 0.070 & 0.023 & 0.045 & 0.061 & 0.037 & 0.060 & 0.087 & 0.017 & 0.032 & - & \\
\hline My & 0.039 & 0.046 & 0.006 & 0.037 & 0.023 & 0.073 & 0.034 & 0.058 & 0.008 & 0.011 & 0.025 & - \\
\hline
\end{tabular}


Table 3. Analysis of molecular variance (AMOVA) (a) between north and south regions and among sites within regions, and (b) between north and south regions and among locations within regions. ${ }^{*} \mathrm{p}<0.00001$

\begin{tabular}{|c|c|c|c|c|c|}
\hline & Source of variation & df & SS & $\begin{array}{c}\text { Variance } \\
\text { component }\end{array}$ & $\begin{array}{c}\% \\
\text { variation }\end{array}$ \\
\hline \multirow[t]{4}{*}{$\mathrm{a}$} & Between regions & 1 & 5.80 & -0.003 & \\
\hline & Among sites within regions & 10 & 68.30 & $0.083^{*}$ & 5.43 \\
\hline & Within sites (= among ind.) & 772 & 1112.74 & $1.441^{*}$ & 94.75 \\
\hline & Total & 783 & 1186.84 & & \\
\hline \multirow[t]{4}{*}{$\mathrm{b}$} & Between regions & 1 & 6.05 & -0.014 & \\
\hline & Among locations within regions & 4 & 44.90 & $0.077^{*}$ & 4.33 \\
\hline & Within locations (= among sites) & 778 & 1229.81 & $1.712^{*}$ & 96.44 \\
\hline & Total & 783 & 1280.77 & & \\
\hline
\end{tabular}

\section{DISCUSSION}

Given that restriction of dispersal and gene flow is common among fragmented or spatially separated populations, we predicted that there would be little connectivity across the $70 \mathrm{~km}$ gap in distribution of the habitat-forming macroalga Phyllospora. Contrary to this prediction, however, there appeared to be much dispersal and gene flow between fragmented populations of this macroalga. Indeed, populations of Phyllospora from the geographically isolated northern region were just as genetically similar to those $>70 \mathrm{~km}$ away in the south as estimate between the sites on either side of the gap in Phyllospora distribution (Shellharbour and Palm Beach) was 0.059, which was not larger than that between any other pair of sites separated by similar distances but between which Phyllospora was present ( $F_{\mathrm{ST}}$ ranged from 0.008 to 0.148 ; Table 2 ).

There was no pattern of isolation by distance, with genetic differentiation $\left(F_{\mathrm{ST}}\right)$ bearing no relationship to geographic distances between sites $(Z=759.31, \mathrm{r}=$ $-0.0143, p=0.524)$. Results of spatial autocorrelation revealed that there was a strong positive correlation among genotypes at distances $<80 \mathrm{~km}$, but no or a random relationship at distances $>80 \mathrm{~km}$ (Fig. 3). they were to neighbouring sites separated by only a few $\mathrm{km}$. Although there was some genetic structure among locations (10s to 100s of km apart) and sites (10s of $\mathrm{km}$ apart), these patterns did not reflect geographic distances.

The apparent connectivity may occur for a number of reasons. First, dispersal may be increased via transport of floating, fertile material that is removed from the substratum during storms. Propagules from fertile algal wrack may be viable for long periods following detachment (Macaya et al. 2005, Hernández-Carmona et al. 2006, Muhlin et al. 2008), and dispersal of floating wrack of other species of fucoid algae has been sug-

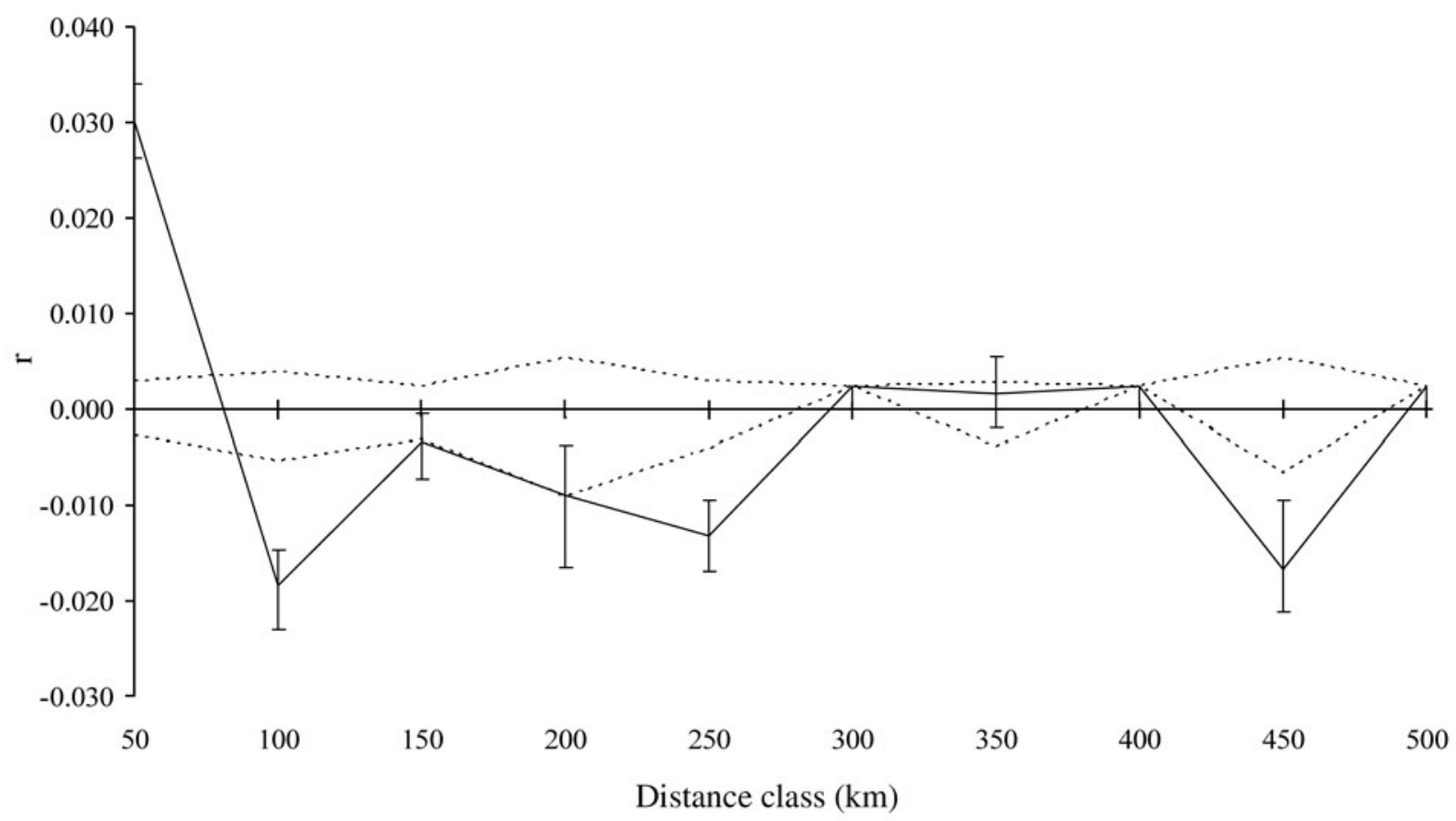

Fig. 3. Phyllospora comosa. Correlogram for all populations sampled along the coast of New South Wales. Dotted lines are upper and lower $95 \%$ CI for the null hypothesis of no structure 
gested to contribute to low levels of genetic differentiation (e.g. Coleman \& Brawley 2005a) even when interbreeding occurs within local populations (Muhlin et al. 2008), as was seen here. Indeed, Phyllospora may be capable of dispersing over vast distances as floating wrack as it has been found on Lord Howe $(\sim 590 \mathrm{~km}$ from the closest extant population of Phyllospora on mainland Australia, NSWA1292, Womersley 1987 and MELUA40649, Millar \& Kraft 1994) and the Norfolk Islands $(1600 \mathrm{~km}$ from populations on the Australian mainland, Millar 1999). Phyllospora wrack has also been found on Sydney beaches despite its absence in neighbouring reefs (M. A. Coleman pers. obs.). Since long-distance dispersal of floating wrack has been observed in other macroalgae (e.g. hundreds to thousands of kilometers; Hobday 2000, Hernández-Carmona et al. 2006), transport of wrack across the $70 \mathrm{~km}$ gap in distribution of Phyllospora may be common.

It is interesting that no pattern of isolation by distance or spatial autocorrelation exists for Phyllospora at scales $>80 \mathrm{~km}$. The apparent patchiness of genetic structure of Phyllospora may be due to fine-scale oceanographic features such as eddies that break off the East Australian Current (EAC). These eddies may promote nonlinear dispersal in 'leaps', sourcing propagules from one area and depositing them sometime later via eddies that either come ashore or disperse, thereby ameliorating any large-scale genetic structure. Similarly, the northward-flowing current that often prevails inland off the coast of NSW (e.g. within 10 nautical miles during southerly winds), may allow dispersal to occur in a direction opposite to that of the EAC. This is likely to occur via floating, fertile drift Phyllospora that are torn from the substratum following storms. Similarly patchy dispersal patterns and gene flow were seen over the same spatial scales in the urchin Centrostephanus rodgersii (Banks et al. 2007) and in the subtidal kelp Ecklonia radiata (M. A. Coleman et al. unpubl.) on the east coast of Australia, as well as in macroalgae in other parts of the world (e.g. Tatarenkov et al. 2007).

As with other fucoid algae (e.g. Kropf 1992, Coleman \& Brawley 2005b), propagules of Phyllospora are likely to settle and attach quickly following release, particularly in relatively warm seawater temperatures on the east coast of NSW. This may explain the paradox of why there was much small-scale genetic differentiation (e.g. among neighboring sites) and positive spatial autocorrelation at distances $<80 \mathrm{~km}$, but no relationship at larger scales. Similarly, strong barriers to dispersal may exist on smaller spatial scales. For example, all adjacent sites were separated by at least one sandy beach, which have been shown to restrict gene flow in other macroalgae (Faugeron et al. 2001, Billot et al. 2003). Many sites were also separated by one or more estuary openings (e.g. Dalmeny and Mystery Bay) across which propagules or fertile wrack must disperse to facilitate gene flow. We suspect that the patterns of genetic differentiation seen here for Phyllospora are caused by different mechanisms of dispersal occurring on different spatial scales. Dispersal of gametes and zygotes may be restricted to small spatial scales (within sites) by the presence of barriers, such as estuaries and beaches, and by rapid fertilisation and attachment of zygotes. On the other hand, fertile wrack, which is likely to be viable for longer periods, may be transported over large distances via currents and contribute to large-scale gene flow. The foregoing may explain the paradox of lower than expected levels of heterogeneity within sites but apparent large-scale dispersal and connectivity. Appropriately designed studies that (1) identify the source and dispersal distance of Phyllospora wrack, and (2) sample across potential barriers to dispersal, such as beaches and estuaries, would be required to test such hypotheses.

Alternatively, the lower than expected levels of heterozygosity and the lack of genetic structure at larger scales in Phyllospora may be caused by homoplasy in allele sizes or a Wahlund effect (Wahlund 1928). Homoplasy in allele sizes, particularly in highly polymorphic loci such as those described here, can explain the apparent lack of large-scale genetic differentiation in other marine organisms (e.g. gorgonian coral, Costantini et al. 2007; planktonic chaetognath, Peijnenburg et al. 2006), and may also explain the paradox of small, but not large-scale structure among populations of Phyllospora. Similarly, a Wahlund effect could arise where the smallest scale in our sampling design (sites separated by $\mathrm{km}$ ) actually encompasses more than one 'real' and ecologically relevant population. Thus, what is interpreted as 'within-population genetic variability' may actually be variability among 2 or more real populations. Sampling on smaller spatial scales would be required to test these hypotheses and tease apart small-scale structure.

The patterns of gene flow and connectivity between fragmented populations of this important habitatforming macroalga are encouraging, particularly since much genetic variability was seen at small spatial scales (among individuals within sites). Apparent longdistance dispersal via floating fertile wrack may eventually facilitate natural recolonisation events onto reefs in Sydney where Phyllospora was once common. Why this has not already occurred is unknown, but this may potentially be due to pre-emptive competition with algal turfs that dominate the space, or other habitatforming algae (e.g. Sargassum, Coleman et al. 2008a) that have increased in abundance where Phyllospora has been lost. Indeed, recolonisation of Phyllospora has been shown to be inhibited by the pre-emptive 
establishment of other species in Tasmania (Valentine \& Johnson 2004). Natural recolonisation in Sydney may, therefore, require intervention or the occurrence of ecological processes that free up space currently occupied by algal turfs (e.g. sand scour or large storm events).

Connectivity among populations is also likely to be beneficial to assisted Phyllospora rehabilitation programs on denuded reefs. The implementation of such programs has received much support from the general public, recreational fishermen and SCUBA divers who would like to see the shallow subtidal reefs of Sydney restored to their former state. Although there are many potential methods of rehabilitating reefs, most methods involve transplantation of adult or juvenile Phyllospora individuals from extant populations. While there is still much to understand about the factors structuring the dispersal of Phyllospora, the present study provides critical genetic knowledge with which to begin the design and implementation of these programs, with appropriate consideration of natural scales of dispersal and gene flow. It will also allow us to reconstruct populations that are as natural as possible with respect to genetic diversity and structure. Use of such genetic knowledge will ensure that rehabilitation programs have the best possible chance of success. With conservation strategies increasingly moving towards the conservation of habitat as opposed to species conservation, the ability to predict the spatial and temporal dynamics of habitat-forming algae such as Phyllospora is of immense benefit to the conservation and management of macroalgal forests, and also for marine biodiversity as a whole.

Acknowledgements. This work was funded by an Australian Research Council Postdoctoral Fellowship to M.A.C. We thank 3 anonymous reviewers for excellent comments and their time in reviewing this manuscript.

\section{LITERATURE CITED}

Airoldi L, Beck MW (2007) Loss, status and trends for coastal marine habitats of Europe. Oceanogr Mar Biol Annu Rev 45:345-405

Banks SC, Piggott MP, Williamson JE, Bove U, Holbrook NJ, Beheregaray LB (2007) Oceanic variability and coastal topography shape local genetic structure in a long-dispersing marine invertebrate. Ecology 88:3055-3064

Belkhir K, Borsa P, Chikhi L, Raufaste N, Bonhomme F (2000) Genetix, a Windows based software for population genetic analyses. Laboratoire Génome, Populations, Interactions CNRS UMR 5000, Université de Montpellier II, Montpellier, France. www.genetix.univ-montp2.fr/partition/partition.htm

Billot C, Engel CR, Rousvoal S, Kloareg B, Valero M (2003) Current patterns, habitat discontinuities and population genetic structure: the case of the kelp, Laminaria digitata in the English Channel. Mar Ecol Prog Ser 253:111-121
Bohonak AJ (2002) IBD (Isolation by distance): a program for analyses of isolation by distance. J Hered 93:153-154

Coleman MA, Brawley SH (2005a) Are life history attributes correlated with patterns of genetic diversity and structure? A case study of Fucus spiralis from the coast of Maine. J Phycol 41:753-762

> Coleman MA, Brawley SH (2005b) Effects of habitat patchiness on population genetic structure of Fucus distichus L. from highshore intertidal rockpools. Mar Ecol Prog Ser 300:63-77

> Coleman MA, Kelaher BP, Steinberg PD, Millar AJ (2008a) Absence of a large brown macroalga on urbanized rocky reefs around Sydney, Australia, and evidence for historical decline. J Phycol 44:897-901

Coleman MA, Dolman G, Kelaher BP and Steinberg PD (2008b) Characterisation of microsatellite loci in the habitat-forming alga Phyllospora comosa. Conserv Genetics 9:1015-1017 doi:10.1007/s10592-007-9437-5.

Costantini F, Fauvelot C, Abbiati M (2007) Phylogeography of the temperate gorgonian coral Corallium rubrum across the western Mediterranean Sea revealed by microsatellites and nuclear sequences. Mol Ecol 16:5168-5182

> Dayton PK, Tegner MJ, Edwards PB, Riser KL (1998) Sliding baselines, ghosts and reduced expectations in kelp forest communities. Ecol Appl 8:309-322

Excoffier L, Laval G, Schneider S (2005) Arlequin ver. 3.0: an integrated software package for population genetics data analysis. Evol Bioinform Online 1:47-50

Faugeron S, Valero M, Destombe C, Martinez EA, Correa JA (2001) Hierarchial spatial structure and discriminant analysis of genetic diversity in the red alga Mazzaella laminarioides (Gigartinales, Rhodophyta). J Phycol 37: 705-716

Faugeron S, Martinez EA, Correa JA, Billot C (2005) Longterm copper mine waste disposal in northern Chile associated with gene flow disruption of the intertidal kelp Lessonia nigrescens. Mar Ecol Prog Ser 288:129-140

Felsenstein J (2002) PHYLIP: Phylogenetic inference package, version 3.6. University of Washington, Seattle, WA

> Frankham R (1998) Inbreeding and extinction: island populations. Conserv Biol 12:665-675

> Gabriel W, Lynch M, Burger R (1993) Muller's ratchet and mutational meltdowns. Evolution 47:1744-1757

Goudet J (1995) FSTAT (ver. 1.2): a computer program to calculate $F$-statistics. J Hered 86:485-486

> Hernández-Carmona G, Hughes B, Graham MH (2006) Reproductive longevity of drifting kelp Macrocystis pyrifera (Phaeophyceae) in Monterey Bay, USA. J Phycol 42:1199-1207

> Hobday AJ (2000) Age of drifing Macrocystis pyrifera (L.) C. Agardh in the Southern California Bight. J Exp Mar Biol Ecol 253:97-114

> Keller LF, Waller DM (2002) Inbreeding effects in wild populations. Trends Ecol Evol 17:230-241

- Kropf DL (1992) Establishment and expression of cellular polarity in fucoid zygotes. Microbiol Rev 56:316-339

- Lande R (1993) Risks of population extinction from demographic and environmental stochasticity and random catastrophes. Am Nat 142:911-927

> Macaya EC, Boltana S, Hinojosa IA, Macciavello JE and others (2005) Presence of sporophylls in floating kelp rafts of Macrocystis spp. (Phaeophyceae) along the Chilean Pacific coast. J Phycol 41:913-922

> Millar AJK (1999) Marine benthic algae of Norfolk Island, South Pacific. Aust Syst Bot 12:479-547

Millar AJK, Kraft GT (1994) Catalogue of marine brown algae (Phaeophyta) of New South Wales, including Lord Howe Island, south-western Pacific. Aust Syst Bot 7:1-46 
Muhlin JF, Engel CR, Stessel R, Weatherbee RA, Brawley SH (2008) The influence of coastal topography, circulation patterns, and rafting in structuring populations of an intertidal alga. Mol Ecol 17:1198-1210

Page RDM (1996) TREEVIEW: an application to display phylogenetic trees on personal computers. Comput Appl Biosci 12:357-358

Peakall R, Smouse PE (2006) GENALEX 6: genetic analysis in Excel. Population genetic software for teaching and research. Mol Ecol Notes 6:288-295

Peijnenburg KTCA, Fauvelot C, Breeuwer JAJ, Menken SBJ (2006) Spatial and temporal genetic structure of the planktonic Sagitta setosa (Chaetognatha) in European seas as revealed by mitochondrial and nuclear DNA markers. Mol Ecol 15:3319-3338

Reynolds J, Weir BS, Cockerham CC (1983) Estimation of the coancestry coefficient: basis for a short-term genetic distance. Genetics 105:767-779

Rice RW (1989) Analyzing tables of statistical tests. Evolution 43:223-225

Saccheri I, Kuussaari M, Kankare M, Vilman P, Fortelius W, Hanski I (1998) Inbreeding and extinction in a butterfly metapopulation. Nature 392:491-494

Soule ME (1980) Thresholds for survival: maintaining fitness and evolutionary potential. In: Soule ME, Wilcox BA (eds). Conservation biology: an evolutionary-ecological perspective. Sinauer Associates, Sunderland, MA

Editorial responsibility: Laura Airoldi, Ravenna, Italy
Steneck RS, Graham MH, Bourque BJ, Corbett D, Erlandson JM, Estes JA, Tegner MJ (2002) Kelp forest ecosystems: biodiversity, stability, resilience and future. Environ Conserv 29:436-469

Tanaka Y (2000) Extinction of populations by inbreeding depression under stochastic environments. Popul Ecol 42:55-62

Tatarenkov A, Jönsson RB, Kautsky L, Johannesson K (2007) Genetic structure in populations of Fucus vesiculosus (Phaeophyceae) over spatial scales from $10 \mathrm{~km}$ to $800 \mathrm{~km}$. J Phycol 43:675-685

Valentine JP, Johnson CR (2004) Establishment of the introduced kelp Undaria pinnatifida following dieback of the native macroalga Phyllospora comosa in Tasmania, Australia. Mar Freshw Res 55:223-230

> van Oosterhout C, Hutchinson WF, Wills PDM, Shipley P (2004) MICRO-CHECKER: software for identifying and correcting genotyping errors in microsatellite data. Mol Ecol Notes 4:535-538

Wahlund S (1928) Zusammensetzung von Population und Korrelationserscheinung vom Standpunkt der Vererbungslehre aus betrachtet. Hereditas 11:65-105

> Weir BS, Cockerham CC (1984) Estimating F-statistics for the analysis of population structure. Evolution 38:1358-1370

Womersley HBS (1987) The marine benthic flora of southern Australia, Part II. South Australian Government Printing Division, Adelaide

Submitted: January 22, 2008; Accepted: February 16, 2009 Proofs received from author(s): April 7, 2009 